\title{
О НЕКОТОРЫХ ВОПРОСАХ, СВЯЗАННЫХ С РАССМОТРЕНИЕМ ЭКОНОМИЧЕСКИХ СПОРОВ МЕЖДУНАРОДНЫМ КОММЕРЧЕСКИМ СУДОМ ПРИ ВЕРХОВНОМ НАРОДНОМ СУДЕ КИТАЙСКОЙ НАРОДНОЙ РЕСПУБЛИКИ
}

\section{ON SOME ISSUES, RELATED \\ TO THE ECONOMIC DISPUTES CONSIDERING BY THE CHINA INTERNATIONAL COMMERCIAL COURT}

A. Iambaev

Summary. The article is devoted to the consideration of organizational and procedural features of China International Commercial Court as a specialized judicial body for proceedings in economic disputes under the China's Belt and Road Initiative. The author raises the question of the importance of special tools for proceedings within interstate integration associations; gives an experience of creating such a body in the People's Republic of China in the form of the International Commercial Court, represented by the two courts in the cities of Xi'an and Shenzhen. The article discusses the goals of the court under discussion and the features of its jurisdiction; shows the court's procedural regulations provisions; describes the technological aspects of the administration of justice by the courts. The author also emphasizes the unification within the court structure judicial and alternative dispute settlement procedures, describing the practical issues of procedures' implementation; refers to the details of a court-based ad hoc committee functioning as an advisory and mediating body; describes how the court chooses the correct applicable law. The author comes to the conclusion that there are both controversial and positive aspects in the peculiarities of the court's operation, focusing on the justification and value of such a mechanism for resolving economic disputes in the context of the Belt and Road Initiative.

Keywords: arbitration, Supreme People's Court of the PRC, Second International Commercial Court in Xi'an, integration, mediation, international economic disputes, Belt and Road Initiative, First International Commercial Court in Shenzhen, «one-stop» application principle, judicial procedures, online court sessions.
H еобходимость проработки существующих механизмов разрешения международных экономических споров, равно как и создание их новых, отвечающих современным реалиям форм, наиболее очевидна в условиях продолжающейся панде-
Ямбаев Алексей Анатольевич Аспирант, Байкальский государственный университет, г. Иркутск iambaev.al@mail.ru

Аннотация. Статья посвящена рассмотрению организационных и процессуальных особенностей деятельности Международного коммерческого суда при Верховном народном суде Китайской Народной Республики как специализированного судебного органа по рассмотрению экономических споров в рамках китайской инициативы «Один пояс, один путь». Автором поднимается вопрос важности наличия специальных инструментов для рассмотрения споров внутри межгосударственных интеграционных объединений, приводится опыт создания такой структуры в Китайской Народной Республике в формате Международного коммерческого суда, представленного двумя судами в городах Сиань и Шэньчжэнь. В статье рассматриваются цели судебного органа, особенности распространения его юрисдикции; приводятся положения процедурных регламентов работы суда; описываются технологические аспекты осуществления судами правосудия. Автор также подчеркивает объединение в структуре суда судебной и альтернативной процедур урегулирования споров, давая описание практическим вопросам их реализации; обращается к подробностям действующего на базе суда специального комитета, функционирующего в качестве консультативного и посреднического органа; описывает способы выбора судом корректного применимого права. В результате автор приходит к выводу о наличии как спорных, так и положительных моментов в особенностях работы рассматриваемого суда, акцентируя внимание на оправданности и ценности существования подобного механизма разрешения экономических споров в контексте инициативы «Один пояс, один путь».

Ключевые слова: арбитраж, Верховный народный суд КНР, Второй международный коммерческий суд в г. Сиане, интеграция, медиация, международные экономические споры, «Один пояс, Один путь», Первый международный коммерческий суд в г. Шэньчжэне, принцип «единого окна», судебный процесс, онлайн-заседания.

мии коронавирусной инфекции [11], обстоятельства распространения и последствий которой по причинам, объективно существующим на рынке товаров, работ и услуг, неизбежно приводят к росту трансграничных споров и связанных с ними юридических проблем 
(банкротство, нарушения договорных обязательств и другие).

Особенно остро потребность в усовершенствовании процесса урегулирования разногласий в экономической сфере стоит перед странами, являющимися участниками международных интеграционных процессов, характеризующихся наиболее тесными межгосударственными связями, при которых происходит масштабное развитие торгово-инвестиционного взаимодействия и усиление бизнес-партнерства в различных областях деятельности. При этом опыт интеграционных объединений доказывает важность создания в системе межгосударственных структур специализированных органов по разрешению таких споров.

Примером данных структур являются Суд Евразийского экономического союза [5], образованный в Минске в 2014 году для разрешения споров, связанных с правоотношениями государств, входящих в данный союз - Российской Федерации, Республики Казахстан, Республики Беларусь, Кыргызской Республики и Республики Армения, а также Экономический суд Содружества Независимых Государств [6], созданный в 1992 году и разрешающий, в соответствии со своими полномочиями, споры, возникающие в рамках исполнения членами Содружества экономических обязательств.

Акцентируя внимание в настоящей статье на процессе интеграции, характерной, по мнению многих исследователей, для современного периода мировой экономики и используемой в качестве актуального формата межгосударственного экономического взаимодействия, представляется целесообразным рассмотреть относительно недавно предложенный Китайской Народной Республикой механизм по урегулированию экономических споров в рамках реализации актуального интеграционного мегапроекта - инициативы «Один пояс, один путь», автором которой и является названная страна.

Так, Китаем в январе 2018 года были опубликованы «Рекомендации по созданию механизма урегулирования коммерческих споров в рамках реализации инициативы «Один пояс, один путь», в которых предлагалось создание качественно новой платформы для решения возникающих споров по принципу «единого окна» нескольких центров, состоящих одновременно из коммерческих судов, коммерческого арбитража и органов медиации, способных коррелировать между собой в зависимости от усмотрения обратившихся сторон. Уже спустя полгода - 29 июня 2018 года, Верховым народным судом Китая объявлено об официальном открытии двух таких государственных центров - Первого международного коммерческого суда в городе Шэньчжэне, провинция Гуандун, и Второго Международного коммерческого суда в городе Сиане, провинция Шэньси [2].

Целями создания данных судов является своевременное и справедливое рассмотрение международных коммерческих дел, обеспечение равной защиты законных прав и интересов китайских и иностранных участников внешнеэкономической деятельности, создание условий для развития стабильной, справедливой, прозрачной и основанной на верховенстве закона бизнес-среды [1]. Рассматривая указанные цели в контексте интеграционного проекта «Один пояс, один путь», видится, что учреждение международных коммерческих судов, с учетом определенных им к рассмотрению категорий споров, должно стать важным шагом на пути к укреплению международного сотрудничества стран-участников китайской инициативы.

В то же время, несмотря на установку Верховным народным судом Китая особого акцента в деятельности новообразованных судов на рассмотрении споров, возникающих в связи с экономическими правоотношениями государств в рамках «Пояса и пути», это не задало жестких рамок специализации данных органов и не обеспечило им особый статус. При образовании двух коммерческих судов было определено, что они являются постоянно действующими судебными органами Верховного народного суда, и непосредственное руководство их деятельностью будет осуществлять его Четвертая судебная палата (коллегия) по гражданским делам.

Проводя аналогию с судебной системой Российской Федерации, Суд по интеллектуальным правам, находясь в системе арбитражных судов и являясь в ней специализированным судом, образованным для рассмотрения определенных категорий споров, тем не менее принимает судебные акты в качестве суда первой инстанции, с возможностью их дальнейшего обжалования в Верховный Суд Российской Федерации, и не ограничен рамками рассмотрения судебных дел, связанных с деятельностью конкретных субъектов права, но подразумевает осуществление правосудия в охвате целого круга правоотношений. Однако, возвращаясь к тематике «Одного пояса, одного пути» в вопросе рассмотрения связанных с инициативой споров международными коммерческими судами Китая, нужно заметить, что сам формат разделения такого органа на два «представительства» обоснован высшим судом страны, в соответствии с идеями председателя КНР, особенностями стратегии «Пояса и пути».

Такие особенности заключаются в двунаправленном развитии инициативы - по сухопутному («Экономический пояс Шелкового пути») и морскому («Морской 
Шелковый путь XXI века») экономическим маршрутам, идеи которых, в соответствии с названиями, вдохновлены направлениями древних караванных дорог Великого шелкового пути.

Таким образом, к рассмотрению Первым международным коммерческим судом Китая, с местом постоянного пребывания в городе Шэньчжэне - крупном прибрежном промышленном и транспортном центре страны, были символически отнесены дела по рассмотрению споров в рамках «Морского Шелкового пути XXI века», а Второй международный коммерческий суд, расположенный в Сиане, древней столице Китая и конечном пункте караванных маршрутов Великого шелкового пути, ориентирован на судебное рассмотрение заявлений в реалиях «Экономического пояса Шелкового пути» [10].

Концентрируясь на практических, процедурных вопросах деятельности рассматриваемых коммерческих судов Китая, следует в первую очередь обратить внимание на юрисдикционные особенности принятия дел к рассмотрению [4].

В соответствии с Постановлением Верховного народного суда Китайской Народной Республики от 27 июня 2018 года, касающегося некоторых вопросов учреждения международных коммерческих судов, коммерческие суды принимают к рассмотрению дела:

- при выборе сторонами юрисдикции Верховного народного суда КНР и сумме требований не менее 300 млн. юаней;

- подлежащие рассмотрению высшим народным судом (третья из четырех судебных инстанций судебной системы КНР), но переданные для рассмотрения Верховному народному суду с его разрешения;

- имеющие важное государственное значение;

- связанные с ходатайствами о «защите собственности» по результатам рассмотрения дела в международном коммерческом арбитраже, об отмене или приведении в исполнение решений международного коммерческого арбитража;

- которые признаны Верховным народным судом целесообразными для рассмотрения Международным коммерческим судом [9].

Кроме того, разъясняя субъектный состав сторон по делам, рассматриваемым международными коммерческими судами Китая, Верховный народный суд указывает четыре фактора, позволяющих признать судебное дело именно международным коммерческим делом.

Так, дело принимается судами к рассмотрению, если одна или обе стороны являются иностранцами, лицами без гражданства, иностранными предприятиями или иными организациями; одна или обе стороны проживают за пределами территории Китая; объект спора находится за пределами Китая; если юридические факты, которые создают, изменяют или прекращают коммерческие отношения, имели место за пределами Китая.

Также важно отметить коллегиальный состав судей, рассматривающих дела, который состоит из трех или более судей. К примеру, при рассмотрении первого дела Международным коммерческим судом при Верховном народном суде КНР, слушания по которому проходили во Втором международном коммерческом суде Китая в Сиане, где ответчиком выступила небезызвестная компания Red Bull Vitamin Drink Co., Ltd., коллегиальный состав рассматривающих дело судей состоял из пяти человек [14]. При этом коллегия в своей деятельности руководствуется правилом большинства.

Изучаемое постановление, посвященное процессуальным вопросам деятельности рассматриваемых судов, состоит из 19 статей, в которых, кроме перечисленных, раскрываются положения, практическое применение которых может значительно упростить процессы расследования, сбора и приобщения доказательств в суде.

Например, допускается возможность озвучивания в зале судебных заседаний доказательственных материалов, возникших за пределами территории Китая, вне зависимости от того, были ли они нотариально удостоверены, а при расследовании и сборе доказательств могут применяться технологии аудиовизуальной передачи информации и другие информационные сетевые методы.

Стоит признать, что указанные процессуальные действия, а именно: расследование, сбор и приобщение доказательств, часто становятся проблемными вопросами при разрешении межгосударственных споров, в том числе - при применении внесудебных способов урегулирования, что влияет на качество отправления правосудия и, соответственно, на уровень доверия органам со стороны субъектов правоотношений. Поэтому так важно организовать беспрепятственное совершение данных действий, что и реализовано в международных коммерческих судах.

Отдельным пунктом нужно выделить обеспечение коммерческими судами удобства ведения судебных разбирательств при помощи специализированных платформ, позволяющих сторонам не только подавать документы и работать с делами в электронном виде, но и участвовать в заседаниях в режиме онлайн, используя доступные устройства. Более того, такой спо- 
соб судопроизводства является в судах общим правилом, а не дополнительной возможностью.

В непростых условиях пандемии подобное внедрение социально значимых технологии является не просто крайне актуальным и удобным инструментом сокращения временных и финансовых затрат, но тем ключом, которым, как предполагается, и должны служить суды, предоставляя возможность гражданам и организациям реализовать, несмотря на внешние условия, свое право на судебную защиту [13].

В этой связи актуально заметить, что Китай не является единственной страной, применившей такого рода новшества в государственных судах. В российской судебной системе в 2020 году также была реализовала технология онлайн-заседаний в судах, которая в дальнейшем может нормативно закрепиться в соответствующих актах.

Тем не менее, с учетом приведенного, давая оценку деятельности Китая в этом вопросе, все же можно утверждать о подчеркнуто значимой пользе онлайн-заседаний, применяемых именно в международных коммерческих судах страны. Говоря об этом и выходя за рамки только обсуждения очевидной ценности технологий в стесненных условиях, нужно принять во внимание трансграничный характер рассмотрения судебных дел в коммерческих судах, в связи с чем принятие мер по установлению доступа для сторон возможности участвовать в заседаниях, не покидая своей страны, способно вывести международный судебный процесс на новый уровень, несомненно, кратно повысив уровень доверия к международным судам и значительно разгрузив суды, что немаловажно для китайской демографической действительности.

Использование таких технологий в Международном коммерческом суде КНР также предусмотрено Правилами судопроизводства в Международном коммерческом суде при Верховном народном суде Китайской Народной Республики от 21 ноября 2018 года [8].

В указанных Правилах разъяснено, что стороны подают свои документы через судебную платформу на официальном сайте суда в сети Интернет [7], и только в случае практической невозможности такой подачи, стороны подают документы при помощи электронной почты, почтового отправления, нарочно или иными средствами, предусмотренными судом.

Также в документе указано, что в целях обеспечения удобства участников судебного процесса судами поддерживаются электронные методы его ведения, используемые, в частности, при принятии дела к про- изводству, оплате госпошлины, уведомлении сторон, ознакомлении с материалами дела, приобщении документов, непосредственном ведении судебного процесса, а, кроме того, и при осуществлении примирительных процедур (статья 4).

Останавливаясь на процедурной части осуществления международными коммерческими судами своих полномочий, стоит обратиться к примечательной особенности данных судебных органов, упомянутой ранее - возможности выбора сторонами в рамках одного органа иных способов урегулирования споров, помимо судебной защиты прав - путем использования коммерческого арбитража или обращения к процедуре медиации.

В первом случае стороны могут договориться о выборе арбитражного учреждения, а также, при необходимости, воспользоваться вышеотмеченными механизмами - обратиться в Международный коммерческий суд Китая с заявлением о принятии мер по «защите собственности» или, в случае несогласия с арбитражным решением - об отмене или приведении в исполнение решений международного коммерческого арбитража.

В случае выбора медиативного инструмента урегулирования разногласий Международный коммерческий суд поручает проведение процедур посредничества членам Международного коммерческого экспертного комитета, учрежденного при Верховном народном суде КНР и состоящего из ученых и экспертов Китая и иных государств, обладающих обширными знаниями в смежных областях (коммерция, международное право и т.д.). Кроме того, стороны вправе совместно выбрать и иную организацию, занимающуюся осуществлением процедуры медиации, включенную в перечень, утвержденный Верховным народным судом.

Если в процессе процедуры медиации стороны заключают мировое соглашение, а, в соответствии с мнением экспертов, практика обращения к такому институту ежегодно только расширяется в Китае, что в том числе обосновано многовековым опытом применения медиации в государстве [3], Международный коммерческий суд запрашивает соответствующие материалы и на основании них выносит решение о заключении мирового соглашения.

Говоря о Международном коммерческом экспертном комитете Международного коммерческого суда Китая, следует отметить, что его работа строго регламентирована. Верховным народным судом сформулированы конкретные правила, касающиеся условий отбора экспертов и рабочих процедур комитета. 
В обязанности комитета, помимо услуг посредничества, которые оказываются не более чем тремя медиаторами одновременно, входит предоставление соответствующих экспертных заключений, например, в отношении применения закона, особенностей международного права и его содержания, а также заключений по толкованию иностранных правовых актов.

Как отметил в декабре 2020 года в своем выступлении судья Апелляционного суда Сингапура Стивен Чонг (庄泓翔), являющийся членом Международного коммерческого экспертного комитета при Международном коммерческом суде Китая, для создания Комитета выбрано самое подходящее время, мировая экономика и культура связаны более тесно, чем когда-либо прежде; ожидается, что инициатива «Один пояс, один путь» обеспечит крупномасштабную торговлю и рост во многих странах Азии, Европы и Африки, а с ростом такой торговли будет соответственно увеличиваться и количество трансграничных коммерческих споров [11].

С учетом членства в Международном коммерческом экспертном комитете представителей различных государств, а следственно, и различных правовых систем, имеющих свои законодательные подходы, например, к выбору применимого права в процессе экономических судебных разбирательств, может встать вопрос о некоторой пристрастности экспертов, которые в деятельности по консультированию судей коммерческого суда могут продвигать интересы своего государства через выбор определенного права, подлежащего применению к экономическим отношениям сторон.

Данный момент был также учтен при образовании судов. В вопросе выбора права, по информации представителей Международного коммерческого суда Китая, суды строго руководствуются «Общими положениями гражданского права Китайской Народной Республики» (приняты на 4-й сессии Всекитайского собрания народных представителей 6-го созыва 12 апреля 1986 года) [16], а также Законом Китайской Народной Республики от 28 октября 2010 года «О праве, применимом к гражданским правоотношениям с иностранным элементом» [17]. Стороны выбирают применимое к отношениям право, руководствуясь перечисленными нормативными актами, поэтому применение судами действующих иностранных законов не исключено; суды уважают и соблюдают принцип автономии воли сторон судебного процесса, пока их выбор обоснован законодательными положениями Китайской Народной Республики [10]; к тому же, при выборе сторонами применимого иностранного права суды тщательно проверяют заявленные требования на их соответствие законодательству выбранного государства, для этого суды могут обратиться к государственным органам стран, имеющих подписанные с Китайской Народной Республикой договоры об оказании правовой помощи [2].

Обобщая особенности Международного коммерческого суда КНР, связанные с универсальностью органа как места проведения различных процедур, нужно сказать, что применение коммерческим судом принципа «единого окна» позволяет избежать распыления в некотором смысле действий участников споров в необходимости удовлетворения своих правовых запросов в разных государственных и частных структурах. Это, безусловно, создает уверенность у сторон, что их попытки мирного урегулирования коммерческих споров, которые, как было отмечено, предполагают наличие крупных финансовых требований, не будут прерваны на каком-либо этапе в связи со сложностью бюрократических процедур.

Для придания данным процессам еще большего удобства Международный коммерческий суд Китая позволяет третейским и посредническим организациям создавать свои офисы в зданиях самих судов, что может усилить позитивный эффект вышесказанного.

Резюмируя обобщенные выше некоторые особенности, связанные с работой образованного в 2018 году судебного органа Китайской Народной Республики, призванного стать новым прогрессивным и универсальным инструментом в не самой простой и прозрачной системе международного права [15], а, кроме этого, со спецификой на рассмотрении дел в рамках интеграционной стратегии «Один пояс, один путь» хочется заметить следующее.

Крупные интеграционные процессы, множащиеся на просторах мировой политико-экономической среды, становятся одним из определяющих факторов развития национальных экономик. В этом контексте инициатива «Один пояс, один путь», с ее сухопутным и морским торговыми маршрутами, не будучи именно международной организацией в привычном понимании, тем не менее по существу своей деятельности является интеграцией и, действуя на передовой в обеспечении благоприятных условий международной торговли и ее расширении, как и любая другая интеграционная стратегия, должна, исходя из самого понятия интеграции, соответствовать определенным критериям.

Одним из таких критериев является создание единых юридических норм, которые должны регулировать определенную часть деятельности членов интеграционного объединения. Видится, что практика создания международных коммерческих судов, при учете всех вызовов, с которыми сегодня сталкиваются судебные системы, и несовершенств уже существующих органов, 
как раз может стать инструментом приближения «Пояса и пути» к соответствию такому критерию.

Конечно, участие в инициативе большинства мировых государств не предполагает установления полноценного единства юридических норм. Кроме этого, существует и ряд других вопросов к китайской идее построения института урегулирования споров «Одного пояса, одного пути», связанных с недоверием участников к самой концепции замены международного института посредничества одним органом, утвердившим определенный список посреднических организаций, а также недоверием к возможности гарантировать беспристрастность и справедливость по отношению ко всем присоединившимся к инициативе странам [12].

В то же время, рассматривая данный вопрос в плоскости, заданной настоящей статьей, необходимо заключить, что четко регламентированная и настроенная на выгоду заявителей система судебной, арбитражной и посреднической процедур, при использовании высокотехнологичных инструментов, способна, как минимум, привести сложные процессы международных тяжб к большей упорядоченности, а также способствовать популяризации уже существующих в подобном формате других иностранных государственных структур.

\section{ЛИТЕРАТУРА}

1. Международный коммерческий суд. [Электронный ресурс]. - Режим доступа: https://chinaperevod.com/info/mezhdunarodnyy-kommercheskiy-sud (дата обращения: 19.03.2021).

2. Международные коммерческие суды в КНР. [Электронный ресурс]. - Режим доступа: https://cnlegal.ru/china_dispute_resolution/international_ commercial_courts_2018 (дата обращения: 20.03.2021).

3. Ракымулы Айтолды. Медиация в Китайской Народной Республике // Вестник Института законодательства и правовой информации РК. - 2020. - № 1 (59). - С. 377.

4. Специальный регламент для международных коммерческих судов в КНР. [Электронный ресурс]. - Режим доступа: https://cnlegal.ru/china_dispute_ resolution/international_commercial_tribunal_procedure_2018 (дата обращения: 19.03.2021).

5. Сд Евразийского экономического союза. [Электронный ресурс]. - Режим доступа: http://courteurasian.org/ (дата 0бращения: 20.03.2021).

6. Экономический суд Содружества Независимых государств. [Электронный ресурс]. - Режим доступа: http://sudsng.org/ (дата 0бращения: 20.03.2021).

7. China International Commercial Court. [Электронный ресурс]. - Режим доступа: http://cicc.court.gov.cn/html/1/index.html (дата 0бращения: 19.03.2021).

8. 最高人民法院办公厅关于印发《最高人民法院国际商事法庭程序规则（试行）》的通知. [Электронный ресурс]. - Режим доступа: http://cicc.court.gov.cn/html/1/218/19/278/1122.html (дата обращения: 19.03.2021).

9. 最高人民法院关于设立国际商事法庭若干问题的规定. [Электронный ресурс]. - Режим доступа: http://cicc.court.gov.cn/ html/1/218/19/278/810.html (дата обращения: 19.03.2021).

10. 常见问题. [Электронный ресурс]. - Режим доступа: http://cicc.court.gov.cn/html/1/218/19/154/index.html (дата 0бращения: 19.03.2021).

11. 莊泓翔: 国际商事法庭的崛起、作用和重要性.[Электронныйресурс].-Режимдоступа:http://cicc.court.gov.cn/html/1/218/62/164/1973. html (дата обращения: 19.03.2021).

12. 威廉 - 布莱尔爵士: 国际商事争议解决的当前热点问题. [Электронный ресурс]. - Режим доступа: http://cicc.court.gov.cn/ html/1/218/62/164/1904.html (дата обращения: 19.03.2021).

13. 伊曼纽尔 - 盖拉德：仲裁程序中新技术的运用. [Электронный ресурс]. - Режим доступа: http://cicc.court.gov.cn/ html/1/218/149/192/1987.html (дата обращения: 19.03.2021).

14. 最高人民法院国际商事法庭敲响 “第一槌” . [Электронный ресурс]. - Режим доступа: http://cicc.court.gov.cn/html/1/218/149/192/1235. html (дата обращения: 19.03.2021).

15. 最高人民法院第一第二国际商事法庭开始正式办公. [Электронный ресурс]. - Режим доступа: https://baijiahao.baidu.com/s?id=160461 2351142042567\&wfr=spider\&for=pc (дата обращения: 19.03.2021).

16. 中华人民共和国民法通. [Электронный ресурс]. - Режим доступа: http://www.npc.gov.cn/wxzl/wxzl/2000-12/06/content_4470.htm (дата 0бращения: 21.03.2021).

17. 中华人民共和国主席令. [Электронный ресурс]. - Режим доступа: http://www.gov.cn/flfg/2010-10/28/content_1732970.htm (дата 0бращения: 21.03.2021). 